\title{
LOS POSTULADOS BÁSICOS DE LA FILOSOFÍA NO-DUALISTA DEL SHAIVISMO DE CACHEMIRA \\ Franz Peter Oberarzbacher*
}

RECEPCIÓN: 24 de septiembre de 2012.

APROBACIÓN: 20 de noviembre de 2012.

* Departamento de Relaciones Sociales, UAM-X. 
CITAM Derechos Reservados.

La reproducción total o parcial de este artículo se podrá hacer si el ITAM otorga la autorización previamente por escrito. 


\section{LOS POSTULADOS BÁSICOS DE LA FILOSOFÍA NO-DUALISTA DEL SHAIVISMO DE CACHEMIRA*}

\section{Propósito}

Sólo del propio Ser puede proceder el conocimiento.

1. El Ser es sin por qué

1.1. La razón no es la explicación del Ser; el Ser es la explicación de la razón.

1.2. El Ser no está atado a ninguna dependencia causal; no tiene principio, ni está condicionado a ninguna finalidad: es supremamente libre.

2. El Ser no está limitado por nada diferente al Ser.

2.1. Nada existe aparte del Ser, o que no sea el Ser.

* Se atribuye a Vasugupta (India, s. VIII) la exposición escrita, en forma de aforismos, de las enseñanzas conocidas como advaita-shaiva, que durante miles de años fueron una sapiencia secreta que se trasmitió oralmente a unos pocos elegidos.

${ }^{1}$ De Jaideva Singh, pueden consultarse: Siva Sútras. The yoga of Supreme Identity, 1979, Delhi, Motilal Banarsidass, y Pratyabhijñáhrdayam. The Secret of Selfrecognition, 1982, Delhi, Motilal Banarsidass; de Swami Muktananda, El secreto de los Siddhas, 1980, New York, Fundación SYDA, South Fallsburg. 
3. El Ser es consciente de Sí mismo (chaitanya).

3.1. El que conoce es el Ser y sólo el propio Ser es conocido por Él mismo. El que conoce el Ser es porque lo es.

3.2. El Ser es Conciencia pura, es decir, no es correlativa a nada que no sea Ella misma. ¿Puede el sol darse luz?

4. La suprema dicha del Ser-Conciencia es amar su Libertad y su libre Poder de Acción.

4.1. Ser-Conciencia-Libertad-Amor-Dicha se copertenecen, son inseparables.

5. Sólo el Ser-Conciencia puede aparecer.

5.1. El Ser-Conciencia es no-forma, nada determinado: sólo así puede aparecer como todas las formas.

5.2. El Ser-Conciencia no depende para su actividad de ningún medio que sea diferente de Sí mismo.

5.3. El Sí-Mismo (Ser-Conciencia) se despliega como el Sujeto (el que percibe) y el Objeto (lo percibido, que no es sino su propia Energía o Poder de Acción).

5.4.1. Entre Sujeto y Objeto se da una perfecta correlación de identidad. El Ser es tanto el Sujeto que percibe como el Objeto percibido. Sólo el propio Ser es el único posible Objeto de percepción. Sujeto y Objeto están mutuamente relacionados como aspectos de la misma Conciencia. La distinción entre Sujeto y Objeto es sólo una distinción entre el Ser-Conciencia y su actividad. El Objeto es la acción misma del Sujeto. El Objeto es la propia energía del Sujeto. Entre el Ser y su Energía no hay separación. El universo es la energía del Sí-Mismo.

5.4.2. El Sí-Mismo abarca al Conocedor-Experimentador, lo Conocido-Experimentado y los medios de Conocimiento-Experimentación. El que conoce y experimenta lo Conocido-Experimentado y los Medios de Conocimiento y Experimentación es siempre el propio Sí-Mismo. El propio Sí-Mismo es quien experimenta en la forma de lo experimentado; es a la vez el que experimenta y el objeto de la experimentación. 
6. El Sí-Mismo despliega el universo a partir de su propio Ser, en su propio Ser y, sin embargo es, a la vez, inactivo. Por su libre poder de acción se autodespliega adoptando una infinita variedad de formas. El universo no es sino la propia energía vibrante (spanda) del Sí-Mismo que nunca está separada de Aquel que la posee. Su energía vibrante recorre, compactándose progresivamente (disminuyendo su "frecuencia"), todos los planos de la existencia (tattvas), hasta desembocar en "materia".

Esencialmente indiferenciado, aparece progresivamente como cada vez más diferenciado. El spanda, a pesar de estar permanentemente presente en el aliento, los pensamientos, sentimientos, emociones, palabras y todas las demás actividades, lo mismo que en cada célula, átomo y partícula atómica, no es percibido en su condición supracausal, por la sencilla razón de que ordinariamente las personas se identifican con el llamado mundo presupuesto. Y a decir verdad, este mundo presupuesto no es más que un espejismo. Sería suficiente con derrumbar el espejismo (maya) para acceder a la Energía en su estado de indiferenciación de la que brotan todas las formas y así el individuo reconocería y tendría la experiencia de la identidad con el Sí-Mismo. Las diferentes vías o medios se adaptan y corresponden a las características y cualidades de cada

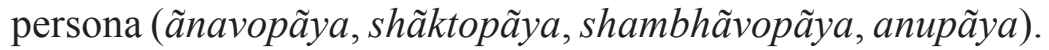

6.1. La Libertad absoluta no admite ninguna diferencia entre Ser y Conciencia, Sujeto y Objeto, Conocimiento y Actividad.

6.2. En cada forma el Sí-Mismo se afirma como su propia forma. Cada individuación es una "corporeización" del Sí-Mismo y, sin embargo, no es reductible a sus individuaciones, pues trasciende a la vez todas las diferencias de las formas.

6.2.1. El Sí-Mismo es inmanente y trascendente e indiferenciado a la vez. Cualquiera que sea la forma que asuma, permanece siempre idéntico a Sí mismo. Su aspecto estático trasciende su aspecto dinámico. ${ }^{3}$

${ }^{2}$ Hay una sorprendente similitud con Meister Eckhart sobre el particular; Eckhart caracteriza esta actividad como bullitio (efervescencia o ebullición) y denomina ebullitio el desbordamiento concomitante, desbordamiento que toma la forma del universo. La bullitio o profusión es la vida única que se desborda como ebullitio o efusión en una multitud de formas de vida. Todas las formas que adopta el universo son sólo variaciones de la Vida única.

${ }^{3}$ El no-dualismo no debe confundirse ni con el panteísmo ni con el monismo, porque sostiene que el Ser es tanto inmanente como trascendente, que es tanto estático como dinámico y, 
FRANZ OBERARZBACHER

7. El Sí-Mismo, al auto-determinarse o al adoptar las formas del universo juega a producir su propio ocultamiento (maya).

7.1. El sostenimiento de la manifestación sólo es posible si el Sí-Mismo se oculta en su aspecto inmanente.

7.2. Sin el juego de su ocultamiento el Sí-Mismo no podría aparecer.

7.3. El Sí-Mismo realiza el acto quíntuple (pañcakrityakãri):

1. Manifestación.

2. Mantenimiento o sostenimiento (la continuidad de la manifestación).

3. Ocultamiento.

4. Disolución o re-absorción de la manifestación.

5. Conciencia de la identidad entre Sujeto y Objeto. ${ }^{4}$

8. En el ser humano, el ocultamiento sólo es mientras éste confina el conocimiento a su percepción sensorial y mental que origina una falsa identificación con su individualidad y exacerba el sentido de diferencia en relación con cada objeto.

8.1. Tiempo, espacio y relaciones causales se convierten entonces para él en los referentes constitutivos de su realidad.

8.2. Considerar los objetos de percepción como diferentes del Sí-Mismo implica seguir confinado al imperio de maya o a la ilusión de la dualidad. El ser humano, aunque no es diferente del Sí-Mismo, ha de convertirse y alcanzar el Sí-Mismo. El juego del Sí-Mismo consiste en esta paradoja.

por lo tanto, no niega la diversidad de las formas. Si se entiende por panteísmo la negación de la trascendencia, nada es más ajeno al no-dualismo; de hecho es su crítica más contundente. El SíMismo no es reductible a la inmanencia, pero tampoco es reductible a la trascendencia. Si estuviera confinado a la trascendencia no habría manifestación o estaría incapacitado para actuar y no tendría relevancia alguna para el hombre. El no-dualismo no es compatible con ninguna modalidad reduccionista. Por otra parte, el no-dualismo no ignora los planos duales, pero supedita el conocimiento racional-discursivo a una forma de conocimiento que lo trasciende. No cabe demostrar al Ser-Conciencia, sólo cabe conocerlo siéndolo. El no-dualismo propone una autoconciencia que se identifica con el Ser-Conciencia mismo.

${ }^{4}$ Hegel propone un esquema parecido. La fenomenología es la ciencia del aparecer del Espíritu cuyos momentos son: 1. Su auto-objetivación y auto-desarrollo de Sí mismo. 2. Su auto-mediación: el Espíritu se proporciona a Sí mismo su esfera objetiva. 3. Su auto-oposición en el plano del principio de no-contradicción. 4. Su auto-extrañamiento o auto-ilusión (como si su objetivación fuera algo diferente a Él mismo). 5. Su auto-realización como Espíritu absoluto o conciliación de Espíritu subjetivo y objetivo. Es a Sí mismo lo que el Espíritu encuentra en el hombre, la naturaleza y la historia porque produce su propio devenir. La multiplicidad es la auto-determinación del Espíritu. 
8.3. A este conocimiento limitado corresponde una libertad limitada que origina insatisfacción y un agudo sentido de carencia. El deseo es el mecanismo para intentar subsanarla.

8.4. Placer y dolor se convierten en los principios rectores de la acción y su sentido.

9. En el individuo humano maya se disuelve por la absorción en el Ser-Conciencia. Conocimiento significa haber logrado la disolución de toda dualidad en la unidad del Ser-Conciencia.

9.1. Conocer el Ser-Conciencia no es diferente de conocerse. ¡Conoce en ti aquello que conociéndolo, todo se torna conocido! (mundaka upanishad).

9.2. Conocerse no es diferente de libertad y dicha.

9.3. Reprimir la actividad de la mente es innecesario, si se ha alcanzado la comprensión de que la Conciencia es su testigo. El conocimiento de la sucesión de los pensamientos no es obra de la mente misma, sino de la Conciencia. La mente es el juego de la Conciencia, es danza de pensamientos.

9.4. La ausencia total de pensamientos permite que la mente se expanda a su verdadero estado, que es el estado de la Conciencia.

9.5. Cuando la mente se vuelve una con la Conciencia, el mundo ya no seguirá siendo el mundo, sino el juego de la Conciencia.

10. El Sí-Mismo en su aspecto trascendente, sin forma, estático e inmanifestado es la Realidad última (chētana, vishvottirna, paramashiva).

11. Por su libre voluntad (svãtantrya, vimãrsha) proyecta el universo con arreglo a una disposición ordenada - que corresponde exclusivamente a su grado de sutileza-, que abarca 118 distintos planos de existencia (bhūvanas) repartidos en 36 determinaciones cualitativas (tattvas).

11.1. El primer tattva se llama shiva tattva. Shiva aparece como "Yo" ( ham), como existencia desprovista de cualquier contenido objetivo (chit, prakasha). 
El $2^{\circ}$ tattva se llama shakti tattva. Shiva se proyecta como "Yo soy" (aham), como Conciencia de lo que existe, como Conciencia de su Poder de Acción, como su poder de aparecer. La shakti es el poder de acción de Shiva.

El $3^{\circ}$ tattva se llama sadãshiva tattva. La experiencia de esta fase es la de: "Yo soy Esto", aham-idam, Yo soy lo que por mi libre Poder de Acción aparece. El énfasis recae en el aspecto "Yo" de la experiencia. El Sí-Mismo se da un "contenido", apareciendo como universo en la modalidad de una objetivación arquetípica o "ideal". El sadãshiva tattva es la primera manifestación (abhãsa).

El $4^{\circ}$ tattva se llama ishvara tattva. Es la fase en la que el énfasis de la experiencia recae en el aspecto "Esto" (idam); la relación es, por tanto, "Esto soy Yo" (idam-aham).

El $5^{\circ}$ tattva se llama sadvidyã o shuddavidyã tattva. En esta fase el aspecto "Yo" (aham) y el aspecto "Esto" (idam) están equilibrados. La experiencia "Yo soy Esto" y la experiencia "Esto soy Yo" es indistinta.

El $6^{\circ}$ tattva es el maya tattva que corresponde al poder del SíMismo de ocultarse ante sus propias objetivaciones. Maya hace posible la ilusoria diferencia entre el Sujeto y Objeto y la oposición entre todas las formas o determinaciones. Con maya surgen las innumerables experiencias de la dualidad, por tanto, de precariedad, carencia, insatisfacción y sufrimiento. Los productos de maya son las cinco "envolturas" (kañchukas) que corresponden a los cinco siguientes tattvas.

El $7^{\circ}$ tattva: kalã es la limitación respecto a la actividad (no omnipotencia).

El $8^{\circ}$ tattva: vidyã es la limitación respecto al conocimiento (no omnisciencia).

El $9^{\circ}$ tattva: rãga es la limitación respecto a la capacidad de gozo y felicidad (no plenitud o perfección).

El $10^{\circ}$ tattva: kãla es la limitación con respecto al tiempo que se divide en pasado, presente y futuro (no eternidad). 
$11^{\circ}$ tattva: niyati es la limitación con respecto al espacio e instaura junto con kála las relaciones de causa-efecto (no omnipresencia).

$12^{\circ}$ El purusha es el tattva que corresponde al Sujeto individual o a la representación y experiencia limitada del aspecto "Yo" (aham) del shuddhavidya tattva, es decir, el $5^{\circ}$ tattva.

$13^{\circ}$ La prakriti es la matriz de la objetividad, por tanto, del espacio, tiempo y causalidad que inciden en la experiencia de la relación, la oposición y la resistencia. Prakriti es el tattva que corresponde a la representación y experiencia limitada del aspecto "Esto" (idam) del $5^{\circ}$ tattva. Los trece siguientes tattvas hacen posible la configuración de la experiencia del sujeto individual llamado antahkarana, que corresponden respectivamente al "aparato psíquico" (chitta) propiamente dicho, que son los tattvas $14^{\circ}, 15^{\circ}$ y $16^{\circ}$, los cinco poderes de la percepción y los cinco poderes de acción, es decir, los tattvas $17^{\circ}$ al $26^{\circ}$.

14: Buddhi es el tattva que corresponde a la capacidad del sujeto individual de intuir, intelegir y recordar.

15: Ahamkãra es el poder de auto-atribución del sujeto individual. Su identidad como individuo la afirma por diferencia respecto a todo otro individuo. El sujeto asume las cualidades de aquello en lo que piensa.

$16^{\circ}$ Manas es el tattva por el cual la mente (el entendimiento) se identifica con lo que piensa. Es también la instancia que admite una objetividad como si ésta tuviera una existencia separada del sujeto. El sujeto supone que está consciente porque algo existe con independencia de él. La dualidad que consiste en un sujeto que percibe y un objeto percibido no es más que un artificio de la mente en la medida que instaura diferencias y oposiciones de conformidad a las exigencias del principio de no-contradicción. Manas se rige, asimismo, por los dictados de la selectividad forzosa y la abstracción. Es el tattva que confirma al individuo en su "egoidad". 
Cada individuo percibe lo que ha proyectado. Lo que proyecta depende del estado en que se encuentra la mente. La proyección retorna como una forma de percepción. La percepción presente corresponde a proyecciones pasadas. Los poderes de la percepción sensorial y sus correspondientes experiencias (jñãnendriyas) son los tattvas del:

$17^{\circ}$ : Olfato.

$18^{\circ}$ : Gusto.

$19^{\circ}$ : Vista.

$20^{\circ}$ : Tacto.

21: Oído.

Los cinco poderes de acción (karmendriyas) y sus correspondientes experiencias son los tattvas:

$22^{\circ}$ : Habla.

$23^{\circ}$ : Manipulación.

24: Locomoción.

$25^{\circ}$ : Excreción.

$26^{\circ}$ : Actividad o reposo sexuales.

90 Los cinco elementos primarios de percepción (tanmãtras) que corresponden a las respectivas facultades de la percepción sensorial son los tattvas del:

$27^{\circ}$ : Sonido en sí.

$28^{\circ}$ : Tacto en sí.

29: Color en sí.

$30^{\circ}$ : Sabor en sí.

$31^{\circ}$ : Olor en sí.

Los tattvas de la materialidad (bhütas) son:

$32^{\circ}$ : Éter.

$33^{\circ}$ : Aire.

$34^{\circ}$ : Fuego.

35: Agua.

$36^{\circ}$ : Tierra. 
11.2. Todo lo que aparece son manifestaciones (ãbhãsas) del SíMismo. Los ãbhãsas no son diferentes del Sí-Mismo a pesar de parecerlo. Todos los ãbhãsas surgen como las olas en el océano. Así como para el océano no hay añadidura, ni disminución con el surgir y disolverse de las olas, tampoco la hay para el Sí-Mismo respecto al surgir y disolverse de los ãbhãsas.

12. Cuando la mente se funde o se absorbe en paramashiva y los dos primeros tattvas, esta experiencia se conoce como sahaja samadhi.

12.1. Cuando la mente se funde o se absorbe en los tattvas $3^{\circ}, 4^{\circ}$ y $5^{\circ}$, la experiencia se conoce como nimilana samadhi, unmilana samadhi y pratimilana samadhi respectivamente.

12.2. Hasta el $5^{\circ}$ tattva inclusive, las experiencias corresponden al plano supracausal.

12.3. Las experiencias del tattva $6^{\circ}$ al $13^{\circ}$, corresponden al plano causal.

12.4. Del $14^{\circ}$ al $21^{\circ}$ corresponden al plano sutil.

12.5. Del $22^{\circ}$ al $36^{\circ}$ al plano físico.

13. Los planos superiores interpenetran siempre a los inferiores, no así a la inversa.

\section{Conclusión}

El conocimiento y experiencia de este proceso por el ser humano constituye su propia esencia. 
CITAM Derechos Reservados.

La reproducción total o parcial de este artículo se podrá hacer si el ITAM otorga la autorización previamente por escrito. 